\title{
Saúde mental da mulher em um contexto de violência doméstica e familiar
}

\author{
Women's mental health in a context of domestic and family violence
}

\author{
Arthur Soares Nunes $^{1}$, Alex Soares Nunes ${ }^{2}$, Maria Janete Cabral $^{3}$, Maria Vilani Soares ${ }^{4^{*}} \bullet$, Rafael \\ Ferro Moura ${ }^{5}$
}

${ }^{1}$ Graduado em Medicina, Universidade Federal do Delta do Parnaíba, Parnaíba, Piauí, Brasil. ${ }^{2}$ Acadêmico de Farmácia, Universidade Federal do Piauí, Teresina, Piauí, Brasil. ${ }^{3}$ Graduada em Enfermagem, Faculdade CET, Teresina, Piauí, Brasil. ${ }^{4}$ Doutora e Mestre em Linguística, Profa. Associada, Universidade Federal do Piauí, Teresina, Piauí, Brasil. ${ }^{5}$ Formando em Psicologia, Universidade Estadual do PiauÍ, Teresina, Piauí, Brasil. *Autor para correspondência. E-mail: mvilasoares@gmail.com.

\begin{abstract}
Resumo: Objetivamos analisar a mulher em um contexto de violência doméstica e familiar, verificando até que ponto a violência por ela sofrida ocasiona problemas de saúde mental, descritos pelo desânimo, agonia e temor, bem como os determinantes que levam a mulher a permanecer nesta relação violenta. Optamos por uma pesquisa de natureza qualitativa, de cunho observacional e descritivo, cujo objeto de estudo são as narrativas de oito mulheres que sofreram e sofrem violência psicológica e que já se encontram comprometidas em sua saúde mental, com sequelas psiquiátricas e emocionais. As entrevistas aconteceram em mulheres vítimas de violência doméstica e familiar, da cidade de Teresina-PI, no ano de 2018. Para a análise das narrativas, consideramos duas categorias: a mulher que sofre e que convive com o agressor e $o$ a mulher vítima que denuncia o agressor. Abordamos como referencial teórico algumas reflexões acerca da Lei Maria da Penha, seus objetivos, eficácia ou falhas na sua aplicabilidade, ressaltando o posicionamento de estudiosos. Constatamos, com este estudo, que nem sempre a mulher consegue denunciar o agressor, dada a situação de violência e de medo em que está inserida. Uma grande parcela das entrevistadas alegou estados de desânimo, agonia e temor como consequências psicológicas e psiquiátricas deste tipo de violência, acarretando-lhes problemas de saúde mental.
\end{abstract}

Palavras-chave: saúde, violência doméstica e familiar, mulher, consequências psicológicas, Lei Maria da Penha.

\begin{abstract}
We aim to analyze the woman in a context of domestic and family violence, verifying the extent to which the violence suffered by her causes mental health problems, described by discouragement, agony and fear, as well as the determinants that lead the woman to remain in this relationship. violent. We opted for a qualitative research, observational and descriptive, whose object of study are the narratives of eight women who suffered and suffer psychological violence and who are already compromised in their mental health, with psychiatric and emotional consequences. The interviews took place with women victims of domestic and family violence, in the city of Teresina-PI, in 2018. For the analysis of the narratives, we considered two categories: the woman who suffers and lives with the aggressor and the woman victim who denounces the aggressor. We approach as a theoretical reference some reflections about the Maria da Penha Law, its objectives, effectiveness or flaws in its applicability, emphasizing the positioning of scholars. We found, with this study, that women are not always able to denounce the aggressor, given the situation of violence and fear in which she is inserted. A large portion of the interviewees claimed states of discouragement, agony and fear as the psychological and psychiatric consequences of this type of violence, causing them mental health problems.
\end{abstract}

Keywords: health, domestic and family violence, women, psychological consequences, Maria da Penha Law.

\section{Introdução}

A violência doméstica e familiar contra a mulher faz parte do cotidiano de muitas brasileiras, sejam estas jovens, adultas ou idosas. Com a Lei Maria da Penha no ordenamento jurídico brasileiro buscou-se atingir equidade e, de fato, proteger e resguardar estas mulheres, apresentando presteza ao processo de investigação e instituindo novas medidas e procedimentos inovadores quanto ao combate à violência doméstica de mulheres privadas de seus direitos. Diante das mobilizações dos movimentos feministas e, em seguida, pelo movimento de caráter internacional, formularam-se acordos e tratados à proteção das 
mulheres, e, mesmo assim, a sociedade não conseguiu dirimir as práticas de violência contra a mulher, daí a necessidade de maiores discussões e reflexões sobre o tema.

Assim este tema configura-se como um problema social, econômico e político que atinge mulheres com idade, grau de instrução, classe social, raça, etnia e orientação sexual diversificados, afetando, cada vez mais, a estrutura familiar. Essa é uma situação que vem se agravando, principalmente, em decorrência do medo, da vergonha, insegurança e até mesmo da falta de conhecimento por parte da mulher, que, muitas vezes, se faz omissa aos seus direitos. Omissão, essa, que, segundo Porto (2007), se dá pelo fato do homem, desde a infância, ter sido educado para saber enfrentar perigos e desafios, já que, até mesmo nas atividades recreativas, este era incitado ao uso da força, ao passo que a mulher, contrariamente, era levada à sujeição e insignificância.

A violência sofrida pela maioria das mulheres dentro do próprio lar faz com que estas vivenciem um desespero silencioso, tornando-as refém das ameaças do seu próprio companheiro. E, nesse desespero, estas se silenciam, se emudecem e não denunciam as agressões, chegando ao ponto de esconder as marcas e cicatrizes físicas no corpo, como também as marcas psicológicas ocasionadas por traumas emocionais, desestruturando-as.

A escolha pela abordagem dos problemas psicológicas causados pela da violência doméstica e familiar sofrida pela mulher se deu pelo fato de serem estas consequências de difícil identificação, podendo trazer graves danos à saúde mental da mulher que convive nesse transtorno silencioso, além de poder configurar o prenúncio de algo mais grave como o feminicídio.

Atentando para tais premissas é que delineamos nossa investigação a partir da seguinte indagação: até que ponto a violência sofrida pela mulher ocasiona problemas de saúde mental, descritos pelo desânimo, agonia e temor, bem como quais os determinantes que levam a mulher a permanecer nesta relação violenta?

Tal problematização parte da hipótese de que nem sempre a mulher consegue denunciar o agressor, dada a situação de violência e medo em que está inserida, cabendo ao profissional que a atende detectar essa necessidade, o que torna ainda mais iminente a necessidade de qualificação desses profissionais.

Buscamos, pois, como objetivo basilar, analisar as narrativas de mulheres que convivem em uma relação violenta no ambiente doméstico e familiar, bem como os danos que essa convivência acarreta à saúde mental da mulher, traduzidos, principalmente, por constantes estados de desânimo, agonia e temor

Para tanto objetivamos, especificamente, descrever as características que são atribuídas à violência doméstica e familiar contra a mulher; identificar quais as consequências da violência doméstica e familiar para a saúde da mulher caracterizadoras de dano emocional e/ou mental; bem como refletir sobre os fatores que contribuem para a permanência da mulher em uma relação violenta.

Optamos por um estudo de natureza qualitativa, do tipo pesquisa de campo e de caráter observacional e descritivo. Nosso intento investigativo parte das narrativas de oito mulheres que sofreram e sofrem violência psicológica e que já se encontram comprometidas em sua saúde mental, com sequelas psíquicas e emocionais.

Consideramos, portanto, para a análise dessas narrativas categorias: a vítima convivendo com o agressor e a vítima denunciando o agressor. Para tanto, seguimos os pressupostos teóricos de autores como Dos Anjos (2006); Miller, 1999; Azevedo (1985); Gomes (1981); Bianchini (2012); Dias (2007); Soares (2006); Day et al (2003).

Assim, para que pudéssemos apresentar ao leitor uma visão mais detalhada de como se deu esta investigação, é que estruturamos este estudo da seguinte forma: abordamos o problema da violência contra a mulher, dando ênfase às formas de agressão, ao ciclo da violência e a alguns dados estatísticos de violência contra a mulher. Dando continuidade, apresentamos a análise dos dados com a descrição do ciclo do medo vivido pelas mulheres entrevistadas e suas consequências psicológicas, seguidas das Considerações Finais, bem como das Referências Bibliográficas.

\section{Metodologia}

Neste estudo, optamos por uma pesquisa de natureza qualitativa, do tipo observacional e de cunho descritivo. Minayo (1994) ressalta que, quando os dados gerados da pesquisa não podem ser quantificados, esta procura uma análise interpretativa dos eventos, considerando-se, assim, seus aspectos qualitativos.

Utilizamos, pois, como instrumento de geração de dados um roteiro de entrevista não estruturada, com seis perguntas abertas, realizada em abril de 2018, na Delegacia de Proteção dos Direitos da Mulher, em Teresina-PI, cujo objetivo foi conhecer as opiniões, crenças, sentimentos, interesses, expectativas, situações vivenciadas das participantes. Abordamos questões pessoais e subjetivas das participantes como sobre o sentimento destas após terem sido vítimas da violência de seus companheiros; o que as levou a denunciar a agressão; o por que de se submeter a viver numa relação de sofrimento e angustia (violência) mesmo sabendo 
que há leis de proteção à mulher; quanto tempo estas convivem com esse sofrimento (violência) até decidirem denunciar; se estas ainda convivem com o agressor; e, somente em caso de a resposta acima ser afirmativa, o que dificulta a decisão de separação.

Abordamos questões pessoais e subjetivas das participantes como sobre o sentimento de vitimização consciente, o que as levou a denunciar a agressão; o porquê de se submeter a viver numa relação de tormento, mesmo sabendo que há leis de proteção à mulher; quanto tempo estas convivem com esse sofrimento (violência) até decidirem denunciar; se estas ainda convivem com o agressor; e, somente em caso de a resposta acima ser afirmativa, o que dificulta a decisão de separação.Nesta investigação, por se tratar de narrativas de mulheres vítimas de violência doméstica e familiar é que se adotou a análise de caráter descritivo e interpretativo dos fatos narrados e do perfil dos participantes da pesquisa, o que ressalta o modo subjetivo do olhar dos pesquisadores.

Tomamos como objeto da análise as narrativas de oito mulheres vítimas de violência doméstica e familiar, de faixa etária entre 18 a 50 anos, sendo que a maioria das participantes não chegaram a concluir o Ensino Médio e grande parte ainda se encontravam convivendo com seus parceiros no momento da pesquisa. Para a análise dos dados, seguimos a metodologia da análise de conteúdo proposta por Bardin (2011). De acordo com o autor o termo análise de conteúdos refere-se às técnicas de análise das comunicações que permitam a inferência de categorias de análise a partir da organização dos dados gerados: (1) A mulher que sofre e que convive com o agressor; (2) a mulher vítima que denuncia o agressor.

\section{Resultados e discussão}

A violência doméstica contra a mulher é reconhecida como um problema social, que prejudica, em demasia, sua integridade emocional, moldada pelo ciclo da violência e os consequentes problemas de saúde psiquiátricas e emocional.

Apresentamos, nesta seção, a análise subjetiva e interpretativa dos pesquisadores em relação às narrativas das oito mulheres que aceitaram participar desta pesquisa. Seguimos a categorização das respostas como apresentamos a seguir. Vale ressaltar que buscamos, também, respaldar as nossas análises nos conhecimentos teóricos dos autores mencionados na seção dois.

\section{A mulher que sofre e que convive com o agressor}

Nesta categoria enquadram-se os questionamentos que dizem respeito ao sentimento da mulher após ter sofrido violência doméstica; o que a levou a denunciar a agressão e o que a levou a viver numa relação de sofrimento e angustia (violência) mesmo sabendo que havia leis de proteção à mulher. Um percentual de $90 \%$ das entrevistadas relatou sofrer de hipertensão arterial, dores de cabeça, ansiedade e distúrbio do sono. Algumas dessas mulheres afirmam que, em decorrência de um desses sintomas, é que foi sugerido a elas a procura por ajuda psiquiátrica.

Um percentual de 90\% das entrevistadas relatou sofrer algum tipo de consequência decorrente da situação de violência. Dentre estas, a hipertensão arterial, dores de cabeça e dificuldades para dormir, foram os sintomas mais relatados. Em alguns casos, a presença de algum desses sintomas contribuiu para a procura de ajuda psiquiátrica.

Algumas mulheres, que corresponde a um total de 40\%, relataram apresentar desânimo como sintoma psicológico. Muitas não apresentavam mais a vontade de realizar o que antes faziam no seu trabalho e até em seus afazeres domésticos. Na maioria das vezes, pegavam-se chorando com facilidade com um derrotismo conflitante.

Ando o tempo todo desanimada, sem vontade pra nada, nem para me arrumar. Não tenho vontade de me arrumar. Às vezes, nem banho tomo. Estou em ponto de enlouquecer, minha vontade é de encher a cara pra esquecer. (32 anos).

Foram mencionados por 15\% das entrevistadas fortes estados de desassossego, aflição, ansiedade, estresse e hostilidade. Estas admitiram impaciência e desassossego com os colegas de trabalho, e entes queridos.

Passei a desconfiar de todo mundo, tratei mal meus colegas de trabalho, meus irmãos, fui ignorante com meus pais e meus filhos. Achava que todos me julgavam e me condenavam. (25 anos). 
Nas falas de $10 \%$ das vítimas, a vulnerabilidade foi uma característica encontrada, uma vez que elas se sentiam fragilizadas, e sem coragem para obter ajuda nesta situação.

Não consigo encontrar uma saída. Tenho receio de que ele me mate. Ando o tempo todo amedrontada, como se estivesse vivendo com o meu maior inimigo. Não sei mais o que fazer, isso tem que acabar. Não consigo pensar em alguém que possa me ajudar. Me sinto indefesa. (23 anos).

Com a saúde mental fragilizada, a mulher sente-se incapaz, incompleta. A ansiedade, o estresse e a depressão assombram a vida destas mulheres. Os dados de mulheres que sofrem com a violência vem aumentando no Brasil. Elas se sentem incapazes de buscarem por ajuda, tornando-se insegura e débil quanto às decisões a serem tomadas. Logo após a agressão é comum ocorrências expressivas em função do trauma como estado de choque ou apatia.

Tenho dificuldades para dormir. Tenho pesadelos com ele arrancando meus olhos e minha língua. Preciso de ajuda médica, talvez algum remédio pra dormir e esquecer de tudo. (23 anos).

Quase não saio mais de casa, também sair pra que, pra ter que me explicar o tempo todo. Eu nem vou mais pra escola, não tenho mais amigos de tanto que me isolei. Fico o tempo todo servindo de "saco de pancada" para ele. Nem no dentista posso ir, já que

Não me reconheço mais, na maioria das vezes não sou mais sou fraca e sem coragem pra lutar, quando me olho no espelho não tenho como me arrumar tenho mais. Ele jogou fora todas as minhas maquiagens. (19 anos).

Segundo Fonseca e Lucas (2006), a mulher consegue vivenciar uma relação que lhe traz dor e sofrimento por muito tempo sem denunciar o agressor. As autoras ressaltam ainda que até quando estas decidem prestar queixa das agressões, são convencidas e "vencidas" (grifo nosso) a desistir. O impressionante na pesquisa de Fonseca e Lucas (2006, p. 14) é [...] que a violência acaba sendo protegida como um segredo, em que agressor e agredida fazem um pacto de silêncio que o livra da punição".

Comentando Dias (2006), as autoras apresentam os vários motivos pelos quais a primeira agressão sofrida, geralmente, não é denunciada: (1) o fato de a mulher aceitar as agressões, por não querer separar-se do companheiro ou, por não querer que ele seja preso; (2) Mulheres justificam as atitudes de violência do companheiro, como ciúme e proteção, acreditando ser demonstrações de amor; (3) Há mulheres que usam os fatores externos, como o estresse do trabalho, das dificuldades financeiras e do cansaço para justificar os atos violentos; (4) Outras colocam o uso de álcool como motivo para explicar as agressões de seus parceiros.

Vivo com meu marido há quase dez anos e desde que casei ele tem um comportamento agressivo. As vezes quando bebe muito quebra tudo dentro de casa. Se eu interferir ele me machuca e me xinga de tudo quanto é nome feio. No início eu achava que era por causa da bebida, mas ele foi se revelando cada ano mais violento. Talvez a culpa seja minha por não ter dado um basta desde o início e por não ter me imposto. (36 anos).

Ele sempre foi ignorante, um animal bruto, mais sempre fazia tudo pela família. De uns dois a cinco anos é que ele mudou. Chega tarde, quando vou reclamar ele me bate na cara, me empurra, diz um monte de palavrão e sempre fede a cachaça. Ele nem me quer mais. Acho que ele tem uma rapariga. Aposto como ele não bate nela. (31 anos)

Hoje vejo o quanto fui burra em acreditar que esse homem me amava demais mesmo me enchendo de porrada... Isso não é amor não, é brutalidade e doença. Quando ele bebe ele se transforma, e quando fica bom diz que me ama. Eu quero mesmo é ficar livre de tanta vergonha... As vezes apanho calada, As vezes apanho calada, só para não ter que sentir a raiva dos meus familiares.. (40 anos) 
Por conta própria, no entanto, o álcool não nos torna violentos ou maldosos. O responsável por isso é a combinação de bebida com situações potencialmente hostis, indesejadas e tensas - soma-se a isso uma personalidade que tem "disposição a agressividade" (ou seja, um impulso para um comportamento violento. (DENSON, 2018). Segundo o autor "[...] o álcool age como um lubrificante que facilita esta agressão subjacente". Muitos dos agressores usam o álcool como "desculpas" para ações violentas, no entanto, eles, quando bebem, já sabem dessa predisposição para ações hostis e se bebem é porque desejam essa hostilidade.

Uma hora ele agride, em outra ele diz que ama e, nessa alternância entre afetos e agressões instala-se o chamado "Ciclo da Violência". Tanto na pesquisa de Fonseca e Luca (2006) como em nossa pesquisa 10\% das mulheres ainda tem a esperança de seus parceiros se arrependam e se harmonizem com a família.

Eu já tentei perdoar, tentei fingir que tudo podia ser diferente, mas ele vinha e fazia tudo de novo... (choro) fazia às vezes até pior. Eu sentia tanto medo. Então ele vinha com aquele jeito dele e me dizia que tava arrependido e quando eu via a gente tava junto de novo. (31 anos)

Outro fator elencado foi o financeiro. Quase $30 \%$ das mulheres dizem depender economicamente do parceiro. Destas algumas não tem emprego e vivem de pequenas atividades domésticas. A maioria destas tem receio de não conseguirem dar o sustento aos filhos e a si. Outras dividem a casa com o agressor por temerem sair e perder a casa, já que alguns deles ameaçam colocar outra no lugar delas.

Vivo nesta situação porque não trabalho e é muito difícil sair de casa e ter que voltar para casa de meus pais junto com meus filhos. Não teria como sair para tentar arrumar emprego, por causa de meus filhos pequenos. (36 anos).

A mulher, após criar vínculo emocional e dependência financeira, na maioria das vezes não consegue romper com o companheiro e, muito menos, se reconhecer vítima de violência.

Já denunciei duas vezes, mas tive que pedir para soltarem. Não consigo emprego porque meu filho é pequeno e não tenho com quem deixar. (20 anos)

Algumas não tem como sustentar os filhos, nem manter a casa, fazendo com que suportem as violências sofridas, sem prestar queixa, ou, quando denunciando, retornam à Delegacia e retiram a queixa, com a desculpa da necessidade da manutenção financeira do companheiro.

\section{A mulher vítima que denuncia o agressor}

Neste estágio, enquadram-se os questionamentos que dizem respeito ao tempo de convivência da mulher com esse sofrimento até decidir denunciar, bem como se ela ainda convive com o agressor.

Em nossas entrevistas, 60\% das mulheres relatam um constante estado de temor e apreensão, pois, temendo que seu parceiro aparecesse a qualquer momento e a agredisse, já que tudo era motivo de castigo. Assim ela se afasta de seus entes queridos e colegas próximos, apavorada temendo o consequente retorno às agressões.

Eu sinto muito medo, minha cabeça vive a mil, vivo assustada. Eu não estou conseguindo trabalhar, nem me deslocar para o meu trabalho, com medo dele me pegar e me agredir. Quando saio do trabalho, fico imaginando ele a minha espera, tenho medo de encontrar ele a qualquer hora.

Todos os sintomas de medo, pânico, temor e agonia, não ocorreu de forma isolada e nem de uma hora para outra. Tudo fazia parte de um ciclo sem fim. As relações de agressão sofridas pelas mulheres favoreceram problemas psiquiátricos e psicológicos.

Hoje tô denunciando ele pela terceira vez... hoje ele me machucou demais, jurou me matar e matar nosso filho... Eu vi o demônio naquele homem... Era uma besta fera que tava ali, não era mais o meu marido. Sei que ele pode me matar e sei que pode matar nosso filho também. Acho que agora ele já foi longe demais. (20 anos) 
A partir das narrativas das participantes, verificou-se que as mulheres, logo depois e tomar a decisão de denunciar, tinham que saber lidar com a vulnerabilidade instalada no pânico de vir a morrer, perder seus filhos e não saber viver sozinha.

Ele sempre sorri pra mim quando eu digo que vou denunciar... ele debocha de mim, diz que vai tirar nossos filhos, pois juiz nenhum vai deixar uma louca criar os filhos sozinha. Ele diz que sou louca porque tomo diazepan passado pelo médico. Tenho medo de ficar sem meus filhos e termino ficando calada. (36 anos)

Todas essas mulheres tem um desejo único: a separação de seus parceiros, no entanto, esta ideia vem sempre acompanhada por sentimento de humilhação, por desonra, impotência, insegurança o que faz com que elas suportem por muito tempo essas agressões, chegando ao limite do adoecimento.

Muitos dos companheiros ameaçam suas mulheres de morte, usando isso, consoante Miller (1999), como um artifício bastante utilizado. Em caso de ameaça grave, a mulher deve procurar imediatamente a polícia e gritar escandalosamente por socorro caso a polícia ainda não tenha chegado. A deve ir à Delegacia mais próxima e abrir um Boletim de Ocorrência, a fim de que sua queixa fique registrada.

Depois que eu denunciei, ele vive me tocaiando pra ver se eu me separei por causa de outro homem. As vezes ele me faz ameaças com faca. Eu corro logo pra casa da minha mãe e mesmo assim ele fica me jurando de morte. (20 anos)

Conforme Fonseca e Lucas (2006), as mulheres mais jovens possuem maior tendência a romper o seu relacionamento com o seu agressor, o que reforça mais cedo o contexto da violência. É importante que a mulher tenha o apoio da sociedade e da família para que ela se sinta forte o bastante para tomar esta decisão de rompimento. Em muitos casos, percebemos que há aquelas que rompem com o relacionamento e, logo em seguida, retornam com seus parceiros por acreditarem que estes terão uma mudança de comportamento. Elas não percebem que esse retorno pode, como adverte Day e outros autores (2003), avolumar as agressões, chegando ao feminicídio.

\section{Considerações finais}

Nesta pesquisa, percebemos, que nem sempre a mulher consegue denunciar o agressor, em decorrência da situação de violência em que está inserida e do medo. Na maioria das vezes, ela vive o que outras pesquisas mostram como ciclo do medo, sofrendo perturbações diante da ideia de que se está exposta a algum tipo de perigo, criando um estado de apreensão, de tristeza, de desânimo, de acomodação, temendo que algo ruim vá acontecer.

Esse sentimento se repete e se enraíza, tornando-a frágil, receosa, assustada, levando-a ao extremo de nem mesmo se ver como vítima, o que responde à problematização deste estudo quando se refere ao problemas psiquiátricos e emocionais como sequelas deste contexto de agressões.

Considerando-se as análises dos relatos das vítimas, percebemos que poucas são as que decidem denunciar o seu agressor e, quando o fazem, rompem com expectativas relacionadas a uma família harmoniosa e feliz, o que causa frustração e depressão, cefaleia, hipertensão, dificuldades para dormir ou problemas mentais mais graves. A frustração e/ou decepção leva a maioria das mulheres ao desânimo, criando obstáculos para que a ela realize o que gostaria de fazer. Isso certamente ocasionaria uma desestruturação emocional com consequências mais sérias, levando-a a fazer uso de medicação.

Por todas estas características, a depressão como doença que pode incapacitar o indivíduo pode comprometer, caso não seja tratada, a saúde física e mental do indivíduo, requerendo auxílio profissional para ser controlada.

Considerando o desenho deste contexto, é que sugerimos a necessidade de se criar mais políticas de atendimento especializado a esse tipo de vítima de violência doméstica e familiar. Esta pesquisa, por si, não se esgota. É importante que mais pesquisas continuem, principalmente elevando o número de participantes entrevistadas, e verificando como, de fato, estão funcionando os programas de assistência à saúde da mulher que é agredida e que sofre violência doméstica e familiar por seus parceiros, de modo que se possa aclarar a dimensão do problema e, portanto, levar à reflexão, informação e criação de estratégias para assistir às mulheres nesta situação. 


\section{Referências}

Aguiar, C. 2002. Guia de serviços de atenção a pessoas em situação de violência. Salvador, BA: Fórum Comunitário de Combate a Violência/Grupo de Trabalho Rede de Atenção.

Azevedo, M. A. 1985. Mulheres espancadas: a violência denunciada. São Paulo, SP: Cortez.

Bardin, L. 2011. Análise de conteúdo. São Paulo, SP: Edições 70.

Bianchini, A. 2012. Os ciclos da violência doméstica contra a mulher. Disponível em: http://atualidadesdodireito.com.br/alicebianchini/2012/02/14/os-ciclos-da-violencia-domesticacontra.

Day, V. P., Telles, L. E. D. B., Zoratto, P. H., Azambuja, M. R. F. D., Machado, D. A., Silveira, M. B., ... \& Blank, P. 2003. Violência doméstica e suas diferentes manifestações. Revista de psiquiatria do Rio Grande do Sul, 25, 9-21.

Denson, T. F., Blundell, K. A., Schofield, T. P., Schira, M. M., \& Krämer, U. M. 2018. The neural correlates of alcohol-related aggression. Cognitive, Affective, \& Behavioral Neuroscience, 18(2), 203-215.

Dias, M. B. 2007. A Lei Maria da Penha na Justiça (2a ed.). São Paulo, SP: Editora Revista dos Tribunais.

Dos Anjos, F. V. 2006. Direito Penal simbólico e Lei de Combate à Violência Doméstica e Familiar Contra a Mulher. IBCCRIM - ANO 14 - No 167.

Fonseca, P. M., \& Lucas, T. N. S. 2006. Violência doméstica contra a mulher e suas consequências psicológicas. (Trabalho de Conclusão do Curso no curso de Psicologia). Salvado, Ba: Escola Bahiana de Medicina e Saúde Pública, Fundação Bahiana para o Desenvolvimento das Ciências.

Gomes, O. 1981. Direito de família. Rio de Janeiro, RJ: Forense, 1981.

Gregori, M. F. 1992. Cenas e queixas: um estudo sobre mulheres, relações violentas e a prática feminista. Rio de Janeiro, RJ: Paz e Terra.

Klingbeil, K., \& Boyd, V. 1984. Emergency room intervention: Detection, assessment and treatment. In A.R. Roberts (Ed.), Battered women and their families: Intervention strategies and treatment programs. New York, NY: Springer.

Miller, M. S. 1999. Feridas invisíveis: abuso não-físico contra mulheres. São Paulo, SP: Summus.

Minayo, M. C. S. 1994. Pesquisa social: teoria método e criatividade (17a ed.). Petrópolis, RJ: Vozes.

Porto, P. R. F. 2007. Violência Doméstica e Familiar Contra a Mulher: Lei $N^{o}$. 11.340/2006: análise crítica e sistêmica. Porto Alegre, RS: Livraria do Advogado Editora.

Soares, L. 2006. O fim do silêncio. São Paulo, SP: Veja.

\section{Minicurrículo}

Arthur Soares Nunes. Graduado em Medicina (Universidade Federal do Delta do Parnaíba), atuando como médico generaliata na cidade de São Pedro do Piauí. Como pesquisador apresentou estudos em Neonatologista, com enfoque em asfixia perinatal.

Alex Soares Nunes. Acadêmico de Farmácia (UFPI).

Maria Janete Cabral. Graduada em Enfermagem (Centro de Ensino Tecnológico do Piauí - CET). PósGraduação em "Saúde Pública com ênfase em ESF” (720h); Pós-Graduação em Enfermagem do Trabalho (360h) e Pós-Graduação em Enfermagem em Neonatologia e Pediatria (UFPI-cursando). Trabalhou no Hospital de Campanha Estadual (HCE/Teresina/2020) no enfrentamento da COVID-19 (UTI). Trabalhou no Hospital Aristides Saraiva (ASA) na cidade de Palmeirais/TE como Enfermeira em Saúde Pública e atualmente como Professora do curso de Enfermagem da Faculdade Estácio. Serviu na Marinha do Brasil (Fortaleza/CE) como recruta/técnico em enfermagem. 
Maria Vilani Soares. Doutora e Mestre em Linguística (UFC); Especialista em Neurolinguística (UFBA) e em Língua Portuguesa (UFPI); Graduada em Letras (UFPI). Atualmente é professora associada do Campus Ministro Petrônio Portela - UFPI- Teresina, lotada no Departamento de Métodos e Técnicas de Ensino (DMTE/CCE). Docente Orientadora do Programa de Iniciação à Docência Letras (PIBID/Capes/UFPI), trabalhando mais especificamente com Pesquisas em Estágio Supervisionado e Formação de Professores. Atuou como Coordenadora do Curso de Letras (CSHNB). Possui experiência na área de Linguística Aplicada ao Ensino de Língua Portuguesa e LIBRAS, com ênfase em Aquisição, Desenvolvimento e Processamento da Linguagem, atuando principalmente nos seguintes temas: escritura e reescritura textual; operadores linguísticos e estratégias textuais; Linguística Cognitiva; Linguística Aplicada ao ensino; Educação e Representação social; Ensino e formação de professores e Métodos e Técnicas da Pesquisa Científica.

Rafael Ferro Moura. Acadêmico de Psicologia pela Universidade Estadual do Piauí. Membro do Laboratório de Psicanálise da Universidade Estadual do Piauí (2017-2019). Membro do Grupo de Estudos "Fundamentos da Psicanálise"

Como citar: Nunes, A.S., Nunes, A.S., Cabral, M.J., Soares, M.V., \& Moura, R.F. 2021 Saúde mental da mulher em um contexto de violência doméstica e familiar, 6, 123. DOI: https://dx.doi.org/10.31533/pubsaude6.a123

Recebido: 3 jan. 2021.

Revisado e aceito: 18 jan. 2021.

Conflito de interesse: os autores declaram, em relação aos produtos e companhias descritos nesse artigo, não ter interesses associativos, comerciais, de propriedade ou financeiros que representem conflito de interesse.

Licenciamento: Este artigo é publicado na modalidade Acesso Aberto sob a licença Creative Commons Atribuição 4.0 (CC-BY 4.0). 